\title{
Applied hermeneutics and qualitative safety data: The CIRAS project
}

\section{Brendan Wallace, Alastair Ross and John B. Davies}

A BSTRACT

KEYW ORDS

\begin{abstract}
This article describes the new qualitative methodology developed for use in CIRAS (Confidential Incident Reporting and A nalysis System), the confidential database set up for the UK railways by the U niversity of Strathclyde. CIRAS is a project in which qualitative safety data are disidentified and then stored and analysed in a central database. Due to the confidential nature of the data provided, conventional (positivist) methods of checking their accuracy are not applicable; therefore a new methodology was developed - the Applied Hermeneutic Methodology (AHM). Based on Paul Ricoeur's 'hermeneutic arc', this methodology uses appropriate computer software to provide a method of analysis that can be shown to be reliable (in the sense that consensus in interpretations between different interpreters can be demonstrated). Moreover, given that the classifiers of the textual elements can be represented in numeric form, AHM crosses the 'qualitative-quantitative divide'. It is suggested that this methodology is more rigorous and philoso phically coherent than existing methodologies and that it has implications for all areas of the social sciences where qualitative texts are analysed.
\end{abstract}

accidents - hermeneutics - interpretation - qualitative quantitative - safety

It has been apparent for some years in the field of the safety management and the sociology of disasters that data about minor events/'near misses' are 
significant in terms of increasing knowledge as to the likelihood of the occurrence of more major events. Incidents such as the space shuttle 'C hallenger' disaster, the Zeebrugge ferry (' $\mathrm{H}$ erald of Free Enterprise') and the $\mathrm{H}$ illsborough football stadium disaster were all preceded by minor error events which, in retrospect, were seen to function as predictors of the disasters in question (Lucas, 1991).

These predictive events were not only important in themselves but also insofar as they pointed to the broader 'systems' issues that are increasingly seen as being important features of accidents and disasters. Important works by Shrivastava (1992) and Vaughan (1996) have demonstrated that major disasters frequently occur in extremely complex socio-technical systems: ('system' used here in the technical sense developed by von Bertalanffy, 1976), and that it may be in large part because these systems are so complex that these events can occur. Theoretical work developed by Reason (1997) and Turner (Turner \& Pidgeon, 1998), has indicated that viewing accidents as merely technical issues fails to identify the key issues that may be of most importance in terms of accident prevention in the future. In fact, as Perrow (1999) argues, adding purely technical 'barriers' to 'technical' problems, may, by making the system more complex and hence difficult to understand, increase the possibility of future accidents.

Therefore it is particularly important to gain access to the systems aspects of minor events (in terms of classification) in order to prevent future disasters. It has been established that a confidential system (that is, a system where reporters are not anonymous, but where their names are not logged, and reports are made anonymous when fed back to management) for logging and analysing minor event data will tend to be more efficient in this respect than a non-confidential system. It is obvious that staff will be more likely to report managerial and systems issues via a confidential system than through 'conventional channels' (Lucas, 1991).

Over the last six years, the CIRAS project (Confidential Incident Reporting and A nalysis System) has created a confidential system for collecting, logging and analysing reports on minor events and other safety issues for the UK railways. The system now covers all companies concerned with the industry. After an initial report has been collected and logged on a M icrosoft A ccess database, a trained interviewer then conducts a longer semi-structured interview either in person or over the phone, in which the safety situation is explained in more depth.

The data are audio recorded and transcribed into texts that are then sent to the Core Analysis facility based at the University of Strathclyde in Glasgow, where they are transferred to the NVivo qualitative analysis package, on which they are analysed. It is important to note that by this time 
the reports have been made anonymous: the Core cannot make contact with reporters. The results of this analysis are then transferred to an SPSS statistical package database: and reports for the industry are written from these data.

In this way CIRAS attempts to combine two main approaches in the social sciences. The first of these is to analyse textual data as qualitative data; that is, a transcription of the actual words used by the interviewee. This verisimilitude is the key attraction of qualitative analysis.

H owever, this advantage could also be seen as a disadvantage, in that the (comparatively) unstructured data produced are so resistant to procedural, ordered analysis. The quantitative approach, on the other hand, has the overwhelming advantage of producing data that are amenable to statistical analysis, something that is particularly important in a safety context. M oreover, it is often simpler to present data in a quantitative form (for example, charts or graphs) than the 'messier' format of qualitative text (for further discussion of this see Robson, 1993: 401-2) This is important given that the 'target audience' in this particular case (safety analysts, safety engineers, and so on) is usually most accustomed to reports containing numerical data.

This begs the question, however, of the 'transformation' process itself: how are qualitative data to be 'turned into' quantitative data? This question has two aspects: first, the practicalities of how the process is to be performed, and second, the theoretical problem of how the process is to be justified, given that the quantitative data are not 'raw' (i.e. from a questionnaire) but have instead to be produced from interviews transcribed as texts.

It is consideration of these two (clearly interrelated) methodological questions that has led CIRAS researchers to an interest in hermeneutics. $\mathrm{H}$ ermeneutics (from the Greek hermeneuien 'to interpret') deals with the problems of interpreting texts and, as it is obvious that in order to transform texts from a qualitative format to a quantitative format they must first be interpreted by a reader, it seems logical that it may throw light on these 'transformation' problems.

\section{Hermeneutics}

H ermeneutics began as the study of religious texts: specifically the 'correct' reading of works such as the Bible or the Torah. This was complicated by their use of parables and allegory: describing the 'correct' interpretation of these for the laity was one of the major functions of the priesthood. $\mathrm{H}$ ermeneutics therefore dealt with two aspects of interpretation which will 
be encountered again: first, the problems of analysing texts in a way that looked beyond the surface features (e.g. of a parable), and second, the problems of verifying the analyses so produced.

It was the philosopher Wilhelm Dilthey (1833-1911) who first began to develop a secularized version of hermeneutics. $\mathrm{H}$ e posited hermeneutics as a way of defending the social sciences from the encroachment of the methodology of the natural sciences, but his basic concerns remained the same as those stated earlier: to what extent are readings to be structured and to what extent are they objectively true or subjectively (relatively) true to the reader?

Twentieth-century hermeneutics oscillated between a neo-Romantic, relativist, strain that emphasized the extent to which interpretation was an individual's, one off act of empathetic interpretation, and a more 'positivist' form that emphasized the extent to which readings were social and structured, and, therefore, could be verified.

It is $\mathrm{M}$ artin $\mathrm{H}$ eidegger who is most strongly linked with the individualistic approach. $\mathrm{H}$ is major work Being and time (Sein und Z eit, 1926/1962) discusses two major issues which are of interest here. The first is the extent to which interpretations presuppose other interpretations. O ur readings of the text in front of us will always be coloured by readings of other texts, in terms of the presuppositions, prejudices and assumptions we make. But these other texts were in turn interpreted in the light of other texts and so on. As $H$ eidegger puts it: 'Interpretation is never a presuppositionless apprehending of something' (H eidegger, 1962: 191-2).

Second, there is the paradoxical concept of the hermeneutic circle. When we read something, we 'break it down' into its component parts (words, paragraphs, and so on). But these parts only make sense in terms of the whole text. There is an endless dialectic, according to $\mathrm{H}$ eidegger, in terms of how we read, between reductionism (breaking the text down) and holism (reading it as a whole).

This has two implications: one positive, and one negative. First there is a paradox: we can never understand a text without breaking it down, and yet we must look at it as a whole before we understand the individual parts. For H eidegger, this is a 'chicken or egg' situation: each step logically presupposes the other. Interpretative reading is therefore a paradoxical action. In order to escape this paradox, we must make a 'leap' of subjective (nonrational) intuition 'into' the text.

However, the correlate of this is that once the reader is 'inside' the circle, understanding can proceed via a dialectical process and, therefore, progress. The text is broken down and then built up again: and each time this is done its 'meaning' becomes clearer.

It is apparent that $\mathrm{H}$ eidegger relativized hermeneutics. If my reading of 
a text is coloured by presuppositions it is obvious that it will be different from yours (with your different presuppositions). So, for H eidegger, reading is not a rational or scientific process, but instead begins with an intuitive 'leap of faith': the only progress I make in understanding is my own personal progress in the hermeneutic circle, but this is essentially a private, not a social process.

The implications of this were brought out by $\mathrm{H}$ ans-Georg Gadamer (1900-2002) who developed H eidegger's thinking in the post-war period.

\section{The theories of Hans-Georg Gadamer}

In his classic work Truth and method (first published in 1960) Gadamer attempted to reinvigorate the hermeneutic tradition by re-emphasizing its subjectivist elements (Gadamer, 1994). So in this work he rejects Realism, and argues that there is nothing except language, the hearing and reading of which only presupposes more language. The assumption of some mysterious 'reality' outside language is a redundant and unprovable hypothesis to Gadamer (Palmer, 1969).

Gadamer's approach may seem extreme but it has a number of advantages for the qualitative analyst. First, it does not necessitate endless attempts to match discourse to 'reality' - an infinitely complex task (for example, in CIRAS, if every event report had to followed up by another report to check its accuracy, since this report would also be a text, it would then have to be followed by another investigation and so on in a situation of infinite regress); and second, it does not support the concept of the 'expert', whose readings are 'better' or 'truer' than other people's. There can be no expert readers for Gadamer, only various readings which have greater or lesser validity for the reader. The main disadvantage of his theories, of course, is that the spectre of relativism remains unexorcized - without 'external reality' perhaps texts can be interpreted to mean anything one wishes.

It is Paul Ricoeur who has attempted to take up this challenge and create a hermeneutic methodology that acknowledges the strengths of Gadamer's arguments but does not result in subjectivist relativism.

\section{The theories of Paul Ricoeur}

Ricoeur does not only attempt to provide an answer to the questions of hermeneutics, he also attempts to provide a method by which hermeneutics may be carried out (Ricoeur, 1981). H is method (which he has termed the 
'hermeneutic arc') has two stages: first a move from the subjective to the objective, and second from the objective to the subjective - thus, according to Ricoeur, preserving the benefits of both approaches.

The initial stage of Ricoeur's approach is to form a hypothesis as to the meaning of a text (on the basis of subjective intuition). This hypothesis must then lead the reader to classify the text into a hierarchy of elements. Despite the fact that Ricoeur admits that in the final analysis texts are polysemous, and that various classifications may be valid, he insists that a social process analogous to that carried out by a court of law can 'test' these hypothetical distinctions. He agrees with Karl Popper that statements must be 'falsifiable', but he does not accept Popper's R ealist assumptions: a reading of a text is falsified if it is internally incoherent or the social 'legal process' rules it implausible.

In the second stage of the hermeneutic arc, Ricoeur analyses the deep structure of a text, which lies underneath its surface structure. Texts are seen to be composed of meaning units that constitute the whole text, in the same way as paragraphs are constituted of words and sentences. These are not what the author 'meant to say' (thus avoiding Gadamer's trap), but instead are formal characteristics that can be studied only in relationship to other aspects of the text (M allery et al., 1987).

Ricoeur therefore believes he has solved the various problems of hermeneutics. Interpretation has been formalized, and can be validated with the same degree of 'objectivity' as any scientific theory. H owever, his method does not presuppose Realism, and does not lead to the paradoxes of 'expert readings' as argued by Gadamer. Instead it breaks texts down, and looks for the deeper, internal structures of meaning which lie inside them.

\section{The purpose of interpretation}

So far problems and methods of interpretation have been discussed. What has not been mentioned is the purpose of interpretation. Texts are not just more or less meaningful, they are also more or less useful. It is important to raise this point because the question of 'objectivity' is difficult to answer unless one knows the social context within which it is being posed. 'W hat is the best reading of this text?' really presupposes that we know 'for what purpose' and 'in what context'. (This point has been raised by Gadamer, who points out that in medieval hermeneutic tradition the third aspect of reading - after understanding and interpretation - was application (Gadamer, 1994: 275).) Therefore, from this point of view, there is no contradiction in positing a practical hermeneutics for a specific social purpose. 


\section{The CIRAS system}

This question is of particular relevance to the CIRAS project in that CIRAS is an example of a situation in which texts are read in a highly specific social context with a highly specific end in mind - namely, to produce data concerning safety (especially the human factors of such) in the rail industry. A method has therefore been developed to read these texts, based on the hermeneutic process described.

The most obvious question to be asked here is, why choose hermeneutics as a basis for the CIRA S methodology? To which the basic answer is that most other interpretation methodologies presuppose Realism, in order to define criteria for reliability and validity of techniques. In other words, they posit the hypothesis that there is a reality 'outside' the text with which the text can ultimately be compared, in order to check whether interpretations are 'true' or not. But the confidentiality aspect of CIRAS means that this is the one approach that is specifically ruled out. M oreover, hermeneutics supposes that this is a problem, and was developed to solve it. This differs from other interpretative strategies whereby the initial philosophical problem is not even stated or faced: for example, grounded theory where

the originators of grounded theory, G laser and Strauss . . . have, in their various works, in effect combined strands of pragmatism, positivism, phenomenology, and hermeneutics, without making any attempt to explain coherently how they tie together.

(Rennie, 1999: 6)

$\mathrm{H}$ ermeneutics is above all a unified coherent approach to the problem.

However, in a sense these defences miss the point. Assuming one accepts the philosophical arguments of the philosophers described, then it follows that all readings are always hermeneutic. There is no option but to choose the hermeneutic approach. For human beings, to exist is to interpret.

\section{The initial process}

The key problem for CIRAS, therefore, in terms of developing a hermeneutic methodology was first of all to create the 'rules' the readers would have to 'follow' in an attempt to create genuine 'objective' (used in the sense that Riceour uses it; i.e. agreed on) readings. There were two specific problems here. The first was to create rules that stayed true to the hermeneutic circle; that is, continually to create movement from micro-units (the individual 
words and sentences of the text) to the macro-unit (the whole text, taken in its entirety). The other problem was to ensure that readers would progress from surface features to depth features: in other words, that the texts would be interpreted not just at a shallow, but also at a 'deep' level.

But, most importantly of all, this methodology had to be developed such that it could be agreed on, and used by all the coders. In other words, we followed Ricoeur in stating that the key aspect of claiming an objectivity in terms of a text's meaning is 'the fixation of the meaning' (Ricoeur, 1977: 328), but this methodology had to be worked out during discussions with all the coders, so a unified methodology (which could be written down in the form of a 'rule book') could be created. It should be noted that we drew mainly on the work of Ricoeur because he has stressed the 'sociological' aspect of hermeneutics, which, due to its emphasis on social, public, and therefore, verifiable readings, is more appropriate to this present project than Gadamer's and H eidegger's thought (which is more 'individualistic'). So how did we 'socially' attempt to 'fix the meaning' of the texts?

First, we created a series of stages of interpretation (easily done within the N Vivo computer software package) in which readers would move from the 'micro-elements' to the whole text. Second, we attempted to ensure that readers moved from 'surface features' to 'deeper structures' in the text.

Therefore, for the first stage, it was decided to create a series of categories of 'surface' 'grammatical' features of the texts. These were simply of the form 'who' 'what' 'where' 'how-why'. In other words, sentences were simply to be read as sentences, with 'how-why' functioning as the verb. So a sample sentence such as 'I drove the set past the red light' would be categorized with 'I' in the 'who' section, 'the set' in the 'what' section, 'red light' in the 'where' section, and 'drove', and 'past' in the 'how-why' section. These are simply 'common sense' grammatical features at the surface level, and were created solely to create a 'close reading' of the 'surface' 'micro-units' of text. This could be done as the first part of the process in the N Vivo software package: with the elements of texts assigned 'coding stripes' (see Figure 1).

The next stage of the methodology was to read the text through again as a whole. Therefore in order to follow the 'rules', readers had to progress from breaking the text down, to building it up again: a continual dialectic between the 'smaller units' and the 'text as a whole' - that is, the hermeneutic circle.

After this, again in NVivo, the text was to be broken down into a 'deeper' level: this time relating to a general reading of the report. This broader structure is the 'frontline', 'supervisory' and 'managerial' distinction. Again, a 'group' judgement was made that the industry could reasonably be broken down into three layers: frontline, supervisory and managerial. 


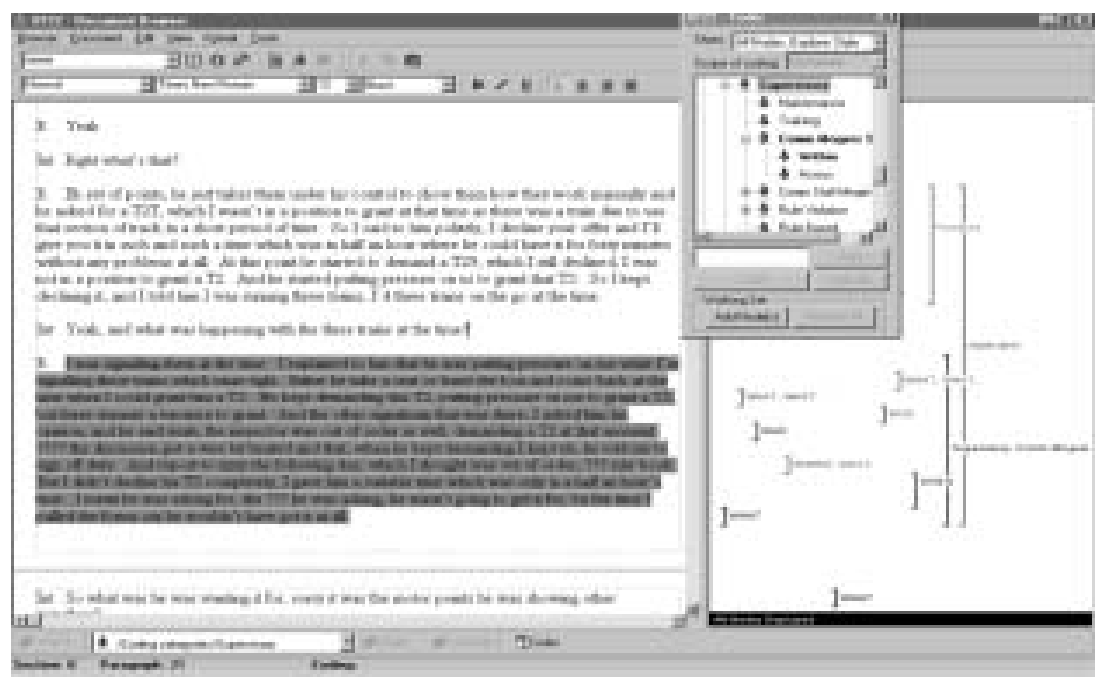

Figure 1 A 'screenshot' of a piece of text being 'coded'. The text is on the left, and the coding is on the right

Frontline issues are concerned with 'workfloor' issues at the 'man-machine' or 'man-task' interface: supervisory issues with supervisors, and (selfevidently) managerial issues with managers. It should be noted that this is a construct specific to this present project. For example, in other industries with different data it might be possible to create a four-tier model, with an added distinction between lower ('middle') management and senior management. These categories are not set in stone, but are reflexive categories functioning as social 'rules' that are decided on by debate.

Again, therefore, the entire text is reviewed in N Vivo and frontline, supervisory and managerial coding stripes (typically larger sections of texts, e.g. paragraphs, would be selected at this stage) are applied. Therefore each relevant section of text is assigned a position at the frontline, supervisory or managerial level.

( $N$ ote: Each element of text may be of any size from sentence to paragraph, depending on its internal structure and degree of coherence. It should be noted that not all the text can be so broken down and that blatantly extraneous material (e.g. discussions about the reporter's pets, or holidays) may be omitted from the 'next phase' of coding at the coder's discretion.)

The next stage in the interpretation process is to take the textual elements from the $\mathrm{N}$ Vivo database and reposition them in a graphical format. Graphics sheets have been created on which 'maps' of the situation are created in terms of the CIRAS matrix. These resemble 'flow charts' as used 
in engineering: however the form of causation used here is social, not mechanical, and deals with social relations (as posited by readers) between elements of texts, not physical causation with mechanical objects. Text fragments are taken and written (by hand) on these forms in order that a graphical representation of the situation is created.

Finally, coders assign a code to the fragments of text that, from the graphical representation, are seen as being the most salient in terms of the purpose of the project. There are 105 discrete codes, which describe a wide variety of human factors, demograpic, and other safety-related data. The categories are (as presented on the coding sheet) personnel, public involved, technical, human factors, feedback, responsibility, avoidance action, environment, consequences. It should be noted that these are used at the coder's discretion: with the exception of the general descriptor (GD) and personnel, there was no category which had necessarily to be used. These codes are contained within a 'coding sheet' that shows them in an easy-to-use hierarchy. Later the codes thus entered on the sheet (which may be paper or in an electronic format) are entered into the SPSS database. Since the 'coding sheet' can be in an electronic format, it is possible to create it such that data are automatically input to the Excel database, and from there to SPSS.

The human factors codes were inferred from a three-by-three matrix which cross-referenced the frontline, supervisory and managerial distinction by an identification of activities as being concerned with job/task, communications, or procedural. It is important to realize that the matrix was developed from the texts, and the texts concentrate overwhelmingly on the 'systems' features discussed earlier (and in works by Reason, 1997 and Toft, 1997), rather than the more traditional 'human error' factors one might expect. In fact, traditional 'cognitive' 'human error' is conspicuous by its absence in reporters' descriptions of events. However, it is interesting that this fits in with current thinking on this subject by writers such as Frese et al. (1991) and Rauterberg (1995), who have emphasized the positive aspect of 'error', especially in terms of learning. Frese draws on H eidegger's concept of 'breakdown': stressing that 'errors' 'help to interpret a habit and thus provide a chance to reflect on the system or on one's own knowledge' (Frese et al., 1991: 79). Therefore, and given that operators who make many errors learn tasks more quickly than those who do not, it seems that the 'error' of many people is not to make errors. This of course calls into question the whole concept, and indicates that the phrase 'human error' is merely wording used in certain social contexts, rather than a genuinely rigorous scientific concept, let alone one that could be quantified. As hermeneutics insists, human behaviour is socially structured behaviour to be interpreted; not determined physical activity to be causally 'explained' (M arch, 1991). 
The matrix, therefore, is sociological and so it has more in common with taxonomies of verbal ethnographic data (e.g. Spradley, 1979) than the more conventional 'causal fault tree' approach. The divisions within the matrix were created from a logical a priori division of activities within the rail company, which presupposed that staff enter into a pre-existing management/organizational structure. This structure, it was argued, had to possess codified rules of behaviour (rules and procedures). The activities that had to be performed within the structure were, logically, of two kinds: either 'physical' 'corporeal' tasks, or else activities concerned with communications. Therefore, an organization had to have procedures (organizational), within which staff carried out tasks (job) and communications. Of course, these were not 'scientific' descriptions of text, but socially negotiated distinctions. The question was therefore not whether they were 'true' but whether pragmatic distinctions could be drawn. And, as we shall demonstrate in the final section of this article, the answer is that they could. A look at the codes themselves should partially give a reason why: even conceptually similar categories such as job/task and communications are quite different at the level of the individual codes.

It is this 'matrix' that functioned as a 'deep structure' to provide the final 'reading' of the text. It should be noted that there was also a 'technical matrix' (as indicated in Figure 3), which divided technical events into operating, transport, and safety systems. These in turn were subdivided further: for example, transport was divided into sets and communication, and operating system was divided into lineside, communication and contractor's (equipment).

The most important point to understand is that these categories (from both matrices) were created by discussion between all the coders, in terms of creating a set of categories that were mutually exclusive but all-inclusive: moreover they were based on initial readings of 10 texts picked at random. In other words, they were based on a social reading of the texts themselves, and the categories were 'set' after a process of discussion: that is, the 'rules' by which the categories were to be applied were written down and became a 'rule book' for coders. By 'mutually exclusive' we mean that definitions were socially created (through debate) such that each definition excluded the others. So part of the definition of 'procedural' errors was 'not job/task' and so on. This methodology was derived from linguistics, where, as Ricoeur argues: 'it is always possible to abstract systems from processes, and to relate these systems . . . to units which are merely defined by their opposition to other units of the same system' (R icoeur, 1977: 334).

The definition as being 'all-inclusive' was again done by studying the texts reflexively and socially and agreeing how they might (if these categories 
were applied) be fitted. Therefore, after many texts had been looked at in this way, it was seen that all logical possible events could be classified in this way, and that, therefore, this would be an accurate categorization system. N ow, when the distinctions had been agreed on (and codified), they could be 'crossreferenced' with the 'frontline, supervisory, managerial' distinction discussed earlier, in order to create the matrix shown in Figure 2.

This 'matrix' is a 'map' of the organization of the industry. It was socially argued and decided on, as was the meaning of each individual code within each 'cell' of the matrix, with these again created in an 'oppositional' sense derived from linguistics as previously described. So, for example, the 'communication' cell at the frontline consisted of two codes: communication between staff, and communication from staff to supervisor/management. Each of these was defined in terms of the other (i.e. if a communication error was between staff, then it could not have been from staff to supervisors, and vice versa).

So we assigned a maximum of three codes within each 'cell' of the matrix, allowing for a maximum of 27 individual human factors codes, each of which could be assigned a numeric value, and thus transferred to the SPSS database. (N ote: For the purpose of analysis these codes were sometimes further subdivided, so, for example, rule violations were either single or common. Therefore there were 32 human factors codes in total.)

At this level, therefore, in NVivo a piece of text, having been 'taken apart' and 'reconstituted' was then 'coded'. 'M edium-sized pieces of text' (normally about the size of a short paragraph, although this was of course

\begin{tabular}{l|l|l|l} 
& Job & Communications & Rules \\
\hline Managerial & $\begin{array}{l}\text { Staffing } \\
\text { Resources }\end{array}$ & $\begin{array}{l}\text { Communication managers-staff } \\
\text { Communication between managers }\end{array}$ & $\begin{array}{l}\text { Rule violation } \\
\text { Procedures/ } \\
\text { documents }\end{array}$ \\
\hline Supervisory & Task management & Communication between supervisors & $\begin{array}{l}\text { Tolerance of } \\
\text { procedural } \\
\text { drift } \\
\text { Rule violation }\end{array}$ \\
\hline Frontline & $\begin{array}{l}\text { Attention } \\
\text { Fatigue } \\
\text { Slips/trips }\end{array}$ & $\begin{array}{l}\text { Communication supervisors-staff } \\
\text { Communication supervisors-management }\end{array}$ & Communication staff-supervisors \\
\hline
\end{tabular}

Note: Some of these codes could be further subdivided: for example, rule violations could be single (a 'one off' event) or common.

Figure 2 The CIRAS human factors matrix 
at the coder's discretion) were assigned a place in the 'matrix': for example, if a supervisor failed to communicate something to staff then it was 'coded' (in NVivo, with a 'coding stripe'), at the supervisory level, then in the communication category. $\mathrm{N}$ ext, given that the text states it was a failure to communicate to staff, this 'code' was applied (in N Vivo). And how was this decision made? As R iceour states, this is a decision of 'subjective probability': is it more or less likely that this particular piece of text fits in this particular part of the matrix, and fits this particular 'code' (Ricoeur, 1977: 331)? This is not the same as a 'positivist' interpretation in which it would either be true or not true that this 'code' was 'correct'. Instead it is a matter of 'more or less likely'. Whether the subjective feelings of the coders agree is a matter for a reliability or consensus trial.

(N ote: A number of other categories - for example, environmental codes, feedback codes (which deal with management response to safety situations), and avoidance codes (dealing with whether or not avoidance action was taken) - also exist. See Figure 3 for a representation of all the coding categories.)

There are a number of points that should be noted here. First, this methodology ensured that readers had to stay true to the 'hermeneutic circle'. To begin with there was the initial reading in which subjective intuition as to the transcript's meaning and purpose was made (this was performed at the point of the initial reading of the short description in the Access database). Then the whole transcript was broken down into 'micro-units' of meaning, which were then related to the meaning of the whole again (considered in the light of the frontline, supervisory, managerial distinction), before being

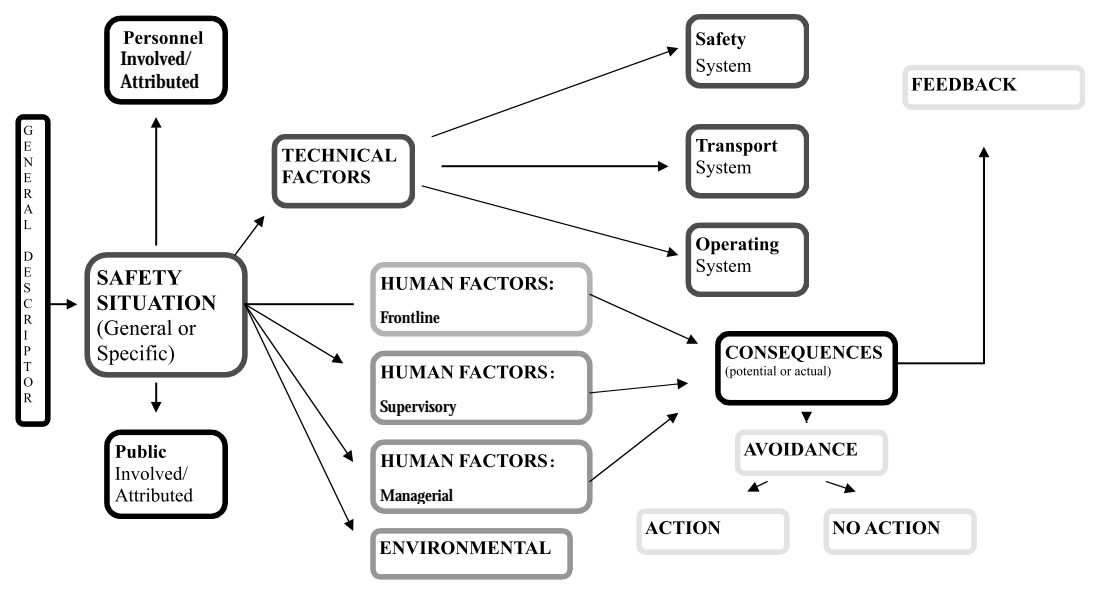

Figure 3 The CIRAS taxonomy. All 'boxes' represent elements from which 'codes' were derived 
related back to individual segments (this time in such a way that fragments of text could be assigned 'codes'). This, according to H eidegger, is the ideal interpretative method.

Second, it is obvious that this methodology was derived from R icoeur's hermeneutic arc. Therefore the basic distinction into how, who and where (etc.) corresponds to his initial hierarchical classification, whereas the reading via the CIRAS matrix reveals the text's deep structure. The matrix and codes are a way of revealing the deeper meanings relevant to safety that might lie underneath the surface linguistic structure: fragments of text are then selected and coded. $\mathrm{N}$ eedless to say they are developed from the matrix, but they are more precise in describing specific fragments of text insofar as they throw light on these underlying meanings.

So the process can be considered from a hermeneutic aspect as follows. First, coders are trained with a codified methodology in a shared social context in an explicit attempt to create shared 'traditions' and 'prejudices' in terms of an approach to the texts. The actual approach to initial texts by a trained coder begins with an initial 'subjective' 'guess' made from the data in the Access database. Once the hermeneutic circle has been entered, the whole (interview) text is then read through. This text is then broken down into surface elements (who, what, where, etc.). It is then reconstituted and read as a whole again before being broken down into elements classified via the matrix. A fter this it is reconstituted, read again, and produced as a graphical representation. Finally it is broken down for the third time into discrete textual elements which are then assigned codes. So the breaking down of the texts into 'surface elements' and then the reading of the whole text is not only the hermeneutic circle, but also constitutes the first phase of the 'hermeneutic arc'. And the breaking down of the text into 'deep structures', and then the reading of the whole text again, constitutes, once more, the hermeneutic circle, and the second phase of the hermeneutic arc.

It must be stressed that codings are not 'correct' or 'wrong'. Instead, as the system is developed, a process of 'juridical reasoning' which has a 'polemical character' is entered into (Ricoeur, 1977: 332), at the level of, first, the basic classifications, then the basic codings applied. $\mathrm{N}$ othing is ever set in stone, and individual coders can always argue that codes 'need to be changed' or that other people's codings are more or less appropriate in a given context.

As an example, therefore, we could take a text produced from an interview. To begin with we have an initial summary of the event (in this case, a signal passed at danger or SPAD). The reading of the summary constitutes the basis for our initial 'leap of faith' into the meaning of the text. Then we read through the text as a whole, before breaking it down into elements that are both 'micro-units' (words) and shallow (not 'meaning units'); that is, the 
'who', 'what', 'why' distinction. Then the text is reconstituted and read as a whole. Then it is broken down again, and looked at in a 'deeper' way: the socially created view of an organization as having a frontline, a supervisory level and a managerial level. Larger elements of text are classified in this way (for example paragraphs). It is then reconstituted and read as a whole again. Third, the text is 'broken down' again into the other three categories procedures, communication and job/task - where the elements of text (from the whole text) are classified in terms of whether the social actions described are seen as being in one or more of these categories. Then it is reconstituted again such that a diagram of it can be drawn: and finally a 'coding' of individual units (phrases and words) leads to the 'coding' that can be input into SPSS as 'quantitative' type data.

To conclude therefore: the process is in six main stages.

1. Initial 'leap' into text from precis written in Access database.

2. Breaking down of text into surface elements.

3. Reading through of whole text.

4. Breaking down of text into deeper structures (once at the level of frontline, supervisory and managerial levels, and then at the levels of procedures, communications and job/task).

5. Reading through of whole text again (and creation of diagram).

6. Breaking down into micro-elements within deeper structures (i.e. codes).

Therefore, stages 2, 3, 4 and 5 are 'the hermeneutic circle'. That is, there is a constant movement from the part (micro-elements) to the whole (the whole text). Also stages 2 and 3 are the first phase of the 'hermeneutic arc', and stages 4 and 5 the second stage.

As an example of the sort of data that can be produced from this process, see Figure 4 (bar chart of general descriptors).

\section{Verification}

This still leaves the problem of verifying the various readings produced, which is particularly important in that CIRAS does not carry out accident investigation. Even if G adamer's objections to R ealism were ignored, it would not be possible to discover whether the reports processed 'matched' or 'reflected' reality. CIRAS is a confidential system and there is no way for coders to return to the interviewee or carry out research to discover what 'really happened'. H owever, regardless of whether there is a criterion of truth, 


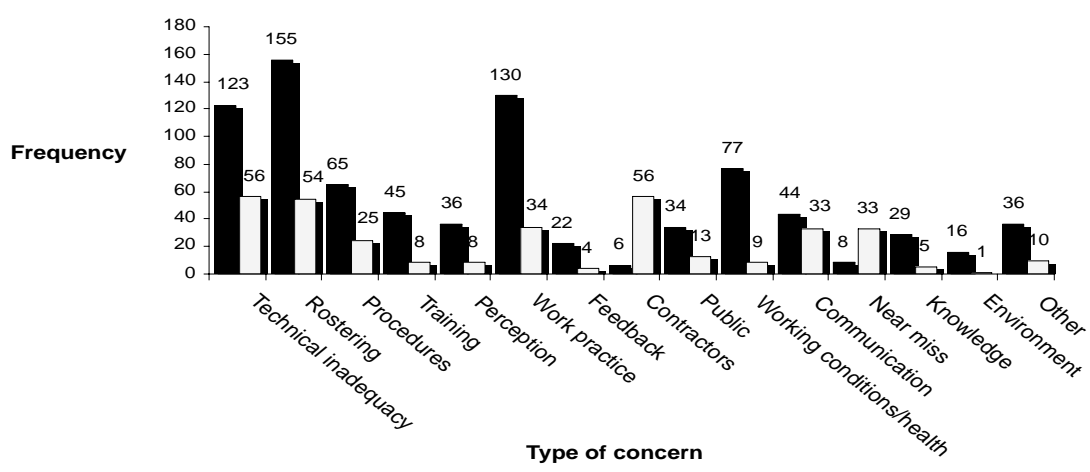

Note: Black bars are general safety concerns: grey bars are specific safety concerns.

Figure 4 An example of CIRAS data: the general descriptors for a specific year

there is a criterion of pragmatics; specifically, how useful these texts are for providing data for the CIRAS model. These data are, of course, then fed back to the rail companies. It is never claimed by CIRAS that reports produced accurately reflect reality, only that they accurately reflect the texts provided.

CIRAS researchers are therefore exempt from Gadamer's critique of Habermas: they do not pretend to be 'experts', nor to know more about railway safety than the people who produce the original data. However, it must be demonstrated that there is sufficient concordance between interpretations such that coders meet the criterion of validity as posited by Ricoeur. Therefore, reliability trials (or to be more precise, trials of concordance or agreement between coders) have been carried out, which test the extent to which CIRAS personnel, using the hermeneutic method detailed, can interpret the same texts in the same way. Because the data produced can be statistically analysed this is easy to do.

It must be stressed that reliability is absolutely essential for testing the degree of concordance between interpretations, especially in a field as important as safety. A s has been argued before, a system such as CIR AS must be able to demonstrate reliability or else validity (functioning effectively) is impossible (Wallace et al., 2002).

It should be noted that these tests can be carried out under strict scientific conditions. The methods of natural science are used to validate the procedure but its Realist assumptions are not. It is not asked whether the data produced are 'objectively true', but it is hoped that they may be objectively the most useful data that can be inferred from the texts in the social context of rail safety. 


\section{The reliability trial}

A trial was therefore carried out at the University of Strathclyde to establish the reliability of the system: it was carried out as follows.

Three coders were trained in the system, a process which took roughly two weeks. They had not been trained in other methods of coding data. Ten randomly selected transcripts were picked from the CIRAS database, none of which had been coded before. The coders were to code the transcripts in the usual way, using all the method steps described here. At the end of the process, they would have a set of codes on the coding sheet, and it was the comparison between these codes that would constitute the test of reliability. The coding sheet included the 'general/specific safety situation' distinction and the general descriptor (GD).

Two things should be noted:

1. Although discussion was allowed after each individual transcript, no discussion of transcripts was permitted before the transcript was coded.

2. Strict scientific conditions were applied: coders were in separate rooms and no communication was possible between them during the trial.

It is suggested that these conditions should be the prerequisites for any further reliability trial of similar coding schemes.

The results of the trial were as follows (see Table 1 ).

Averages were calculated using the Index of Concordance: $A(A / D)$. Totals were calculated such that the coders were 'paired' with each other. So the results of coder A's agreement with coder B were calculated, then the agreement with coder $B$ and $\operatorname{coder} C$, and so on. This was to avoid the simple error of assuming that, for example, if two coders agree and one disagrees this is an agreement of 66 percent. It is, of course, 33.33333 recurring percent (because coder $A$ has disagreed with coder $B$, and coder $C$ has disagreed with coder $A$ : leaving only one agreement: between coders $B$ and $C$ ).

In this trial, the average between the three coders was 71.73 percent.

Table 1 Results of the reliability ('consensus') trial

\begin{tabular}{lllllllllllll}
\hline Trial & 1 & 2 & 3 & 4 & 5 & 6 & 7 & 8 & 9 & 10 & Average \\
\hline ab & $100 \%$ & 78.57 & 72.20 & 87.50 & 55.55 & 87.50 & 66.66 & 75.00 & 73.30 & 68.75 & 76.50 \\
ac & $69.23 \%$ & 38.46 & 63.63 & 70.00 & 55.55 & 100 & 80.00 & 53.80 & 78.60 & 64.30 & 67.38 \\
bc & $\begin{array}{l}69.23 \% \\
35.71\end{array}$ & 60.00 & 77.77 & 100 & 87.50 & 68.40 & 54.50 & 78.60 & 71.40 & 71.31 \\
Total & 71.73 & & & & & & & & & & \\
\hline
\end{tabular}




\section{Conclusion}

In a standard work on research, Borg and Gall (1989) state that reliability of over 70 percent is acceptable in this context. By this criterion the applied hermeneutic methodology (AH M) used at CIRAS has clearly been shown to be reliable.

Although CIRAS has been shown to be reliable, this does not of course mean that the system is therefore necessarily valid. As has been argued previously, reliability is a necessary, though not sufficient, condition for validity. Both, how ever, are necessary to demonstrate the effectiveness of a system.

Salkind (2000) describes two basic kinds of validity: criterion validity and construct validity. Criterion validity in this case deals with the extent to which the data are pragmatically useful. There are two aspects of this for CIRAS. At the 'micro-level' it would deal with situations in which specific texts (interviews) were processed by CIRAS, which then led to feedback to the companies responsible in such a way that the situation was seen to be satisfactorily ended, and specific examples of this have occurred. $\mathrm{O} n$ a wider scale, this would be when broader industry safety issues were highlighted and fed back to management. It would be hoped that remedial action by management would then result in a positive impact on the database in this particular respect. W hile the database is at present too new for this to have occurred yet, it is hoped that this form of validity will eventually be obtainable.

The second form of validity - construct validity - can be described as the extent to which the data model the 'safety situation' that actually exists. $\mathrm{N}$ eedless to say this is problematic considering the epistemological and ontological assumptions used in CIRAS as described earlier. However, one obvious way to analyse it on at least one level would be to see to what extent the CIRAS database produced a model that was compatible with other models that might be seen to analyse comparable data (i.e. whether it 'coheres' with other sources of knowledge; Rescher, 1973).

It can be seen that the CIRAS database functions, because of the organizational features of the 'matrix', as a sociological model of an organization: in this case, the British railways. M oreover, unlike most such models, it is theoretically valid (as has been argued), empirically valid (because information from reports is continually coming in) and dynamic. The CIRAS database is always changing, always mirroring the reports. It is hoped that long-term trending data may be generated, in order to produce a validated dynamic sociological model of the organization, developed through reliable hermeneutic interpretations. Of course, these may then be compared with other databases produced by the same method in other organizations. It is 
hoped that this will prove to be a breakthrough in the sociology of organizations and disaster management.

As well as this, we would argue that the concept of 'human error' should be reviewed. M uch work in this field has been done by psychologists, who have, understandably, attempted to describe what 'causes' 'mistakes' made by individuals. We would argue that a 'social systems' approach (such as that advocated by R eason, 1997) might produce more pragmatically useful results. Perhaps it is a failure to acknowledge systems issues that has led to the difficulties in achieving organizational change detailed by Svyantek and DeShon (1993).

Moreover, we would argue the use of hermeneutic methods for analysing human behaviour, such as those used by Winograd and Flores (1986) and Frese et al. (1991), may give new insights into the psychology of accidents: Frese's use of H eidegger's concept of breakdown is of interest here. This work may not only lead to more empirical, laboratory studies, but also to investigations into the relationships between these studies and hermeneutic databases such as CIRAS.

Finally there are the implications for hermeneutics. While it has often been claimed that a hermeneutic approach to texts can produce data as reliable as those produced with 'scientific' methods (chiefly, of course, by those in the tradition of Ricoeur, as opposed to H eidegger and Gadamer), this has been more often talked about than done. Perhaps this is due to a feeling that it would introduce an over-'scientistic' approach to a tradition that developed as an alternative to western concepts of science. This of course assumes that the 'hard' sciences are in fact the positivistic activities they are sometimes claimed to be, in the face of the evidence of social creation of pragmatic consensus (by N ASA engineers) detailed by Vaughan (1996). Be that as it may, a trial of agreement or concordance merely shows the degree to which members of a social group agree with each other in terms of interpretation. It does not at all imply that this view point is 'correct' or 'true'. Therefore, it is not the case that high reliability is somehow compromising the hermeneutic process. M oreover it must be stressed that the process must remain open, social and democratic: reflexive, but socially reflexive, not individually so. If the group were to decide that the fundamental categories were to be revised it must always be possible to do so in the face of texts that are difficult to interpret. If this were not the case the whole point of a hermeneutic approach would be lost.

Given that this is the case, it is hoped that the applied hermeneutic methodology (as described here) has justified itself, not just in human factors but in many other areas of research, and that, therefore, it can take its place as an appropriate research tool for a 21st-century social science. 


\section{Bibliography}

Bernstein, R. Beyond objectivism and relativism. Philadelphia: University of Pennsylvania Press, 1983.

Bleicher, J. Contemporary hermeneutics. London: Routledge \& Kegan Paul, 1980.

Borg, W. \& Gall, M. Educational research. London: Longman, 1989.

Frese, M., Brodbeck, F., H einbokel, T., M ooser, C., Schleiffenbaum, E. \& Thiemann, P. Errors in training computer skills: $\mathrm{O} n$ the positive function of errors. H uman-Computer Interaction, 1991, 6, 77-95.

Gadamer, H.-G. Truth and method, 2nd revised edn. Translation revised by J. Weinsheimer \& D.G. M arshall. N ew York: Continuum, 1994. (First published 1960.)

Habermas, J. A review of Gadamer's Truth and method. In F. Dallmayr \& T. M cCarthy (Eds), Understanding and social enquiry. London: University of $\mathrm{N}$ otre Dame University, 1977.

$\mathrm{H}$ ans, J. The question of value. Carbondale: Southern Illinois University Press, 1989.

H eidegger, M. Being and time. London: SCM Press, 1962. (First published 1926.)

$\mathrm{H}$ ekman, S. H ermeneutics and the sociology of knowledge. Oxford: Polity Press, 1986.

H SE. Successful health and safety management. London: H SE Books, 2000.

H utter, B.M . Regulation and risk. O xford: Oxford University Press, 2001.

Lakoff, G. \& Johnson, M. Philosophy in the flesh. N ew York: Basic Books, 1999.

Lucas, D.A. Organisational aspects of near miss reporting. In T.W. van der Schaaf, D.A. Lucas \& A.R. H ale (Eds), N ear miss reporting as a safety tool. Oxford: ButterworthH einemann, 1991, pp. 127-47.

M allery J.C., H urwitz, R.\& Duffy, G. H ermeneutics: From textual explication to computer understanding? In S. Shapiro (Ed.), The encyclopaedia of artificial intelligence. $\mathrm{N}$ ew York: John Wiley and Sons, 1987. Available online at http://www.ai.mit.edu/ people/jcma/papers/1986-ai-memo-871

M arch, J. H ow decisions happen in organizations. H uman-Computer Interaction, 1991, 6, 95-119.

Palmer, R. H ermeneutics. Evanston, IL: N orthwestern University Press, 1969.

Perrow, C. N ormal accidents: Living with high-risk technologies. Princeton, N J: Princeton University Press, 1999.

Pidgeon, N. The limits to safety? Culture, politics, learning and man-made disasters. The Journal of Contingencies and Crisis M anagement, 1997, 5(1), 1-13.

Rauterberg, M. A bout faults, errors, and other dangerous things. In C. N tuen $\&$ E. Park (Eds), Human interaction with complex systems: Conceptual principles and design practice. N orwell: Kluwer, 1995.

Reason, J. M anaging the risks of organizational accidents. Aldershot: A shgate, 1997.

Rennie, D. Q ualitative research: A matter of hermeneutics and the sociology of knowledge. In M . Koppala \& L. Suzuki (Eds), U sing qualitative methods in psychology. Thousand Oaks, CA: Sage, 1999.

Rescher, N. The coherence theory of truth. Oxford: Oxford University Press, 1973.

Ricoeur, P. The model of the text: M eaningful action considered as a text. In F. Dallmayr $\& \mathrm{~T}$. M cC arthy (Eds), Understanding and social enquiry. London: University of $\mathrm{N}$ otre Dame Press, 1977.

Ricoeur, P. Hermeneutics and the human sciences. Cambridge: Cambridge University Press, 1981.

Robson, C. Real world research. Oxford: Blackwell, 1993.

Salkind, N. Exploring research. Englewood Cliffs, N J: Prentice H all, 2000.

Shrivastava, P. Bhopal: A natomy of a crisis. London: Paul Chapman, 1992.

Shrivastava, P., M iller, D. \& M iglani, A. The evolution of crises: Crisis precursors. The International Journal of M ass Emergencies and D isasters, 1991, 9(3), 321-37.

Spradley, J. The ethnographic interview. O rlando, FL: H arcourt, Brace, Jovanovich, 1979. 
Svyantek, D. \& DeShon, R. O rganizational attractors: A chaos theory explanation of why cultural chance efforts often fail. Public A dministration Q uarterly, 1993, Fall, 338-55.

Taylor, D.H. The hermeneutics of accidents and safety. In J. Rasmussen, K. Duncan \& J. Leplat (Eds), N ew technology and human error. Chichester \& N ew York: Wiley, 1987.

Toft, B. Learning from disasters: A management approach, 2nd edn. Leicester: Perpetuity Press, 1997.

Turner, B. Causes of disaster: Sloppy management. British Journal of M anagement, 1994, 5, 215-9.

Turner, B. \& Pidgeon, N. M an-made disasters. Oxford: Butterworth-H einemann, 1998.

Vaughan, D. The Challenger launch decision. Chicago: University of Chicago Press, 1996.

Von Bertalanffy, H. G eneral systems theory: Foundations, development, applications. N ew York: George Braziller, 1976.

Wallace, B., Ross, A., Davies, J.B. \& Wright, L. The creation of a new minor event coding system. Cognition Technology and Work, 2002, 4, 1-8.

Winograd, T. \& Flores, F. Understanding computers and cognition: A new foundation for design. N orwood, N J: A blex, 1986.

Brendan Wallace has a PhD in English Literature and an MPhil in Research Methods in the Social Sciences, both from the University of Glasgow, UK. He developed the national CIRAS project with Alastair Ross at the University of Strathclyde, and has also worked on various other safety and health related projects. He has co-written a book entitled Safety management: A qualitative systems approach with Alastair Ross, John Davies and Linda W right, published by Taylor \& Francis.

[E-mail: brendan.wallace@ strath.ac.uk]

Alastair Ross is a Senior Research Fellow in the Centre of Applied Social Psychology (CASP) at the U niversity of Strathclyde in G lasgow, UK. $\mathrm{He}$ has developed taxonomies and coding systems for a number of highconsequence industries. He has an interest in discourse and attribution, in particular the psychology of sport and the way in which natural explanations of elite athletes relate to subsequent performance.

[E-mail: alastair.j.ross@ strath.ac.uk]

John B. Davies is D irector of the Centre of Applied Social Psychology (C ASP) at the University of Strathclyde in G lasgow, UK. He has an extensive research and publication record in the area of human factors and public health and has contributed widely to national and international conferences on both these topics. He is also Director of Human Factors A nalysts Ltd (HFAL).

[E-mail: j.b.davies@ strath.ac.uk] 